\title{
HLA status and lymphocyte phenotypes in gastric cancer
}

\section{ORIGINAL ARTICLE Annals of Cancer Research and Therapy}

\author{
Kyoji Ogoshi · Masao Miyaji · Kenji Nakamura · Yasuo Kajiura · \\ Yasumasa Kondoh · Tomoo Tajima - Toshio Mitomi*
}

\begin{abstract}
To evaluate the association between HLA status and cell-mediated immunity, we examined the lymphocyte phenotypes and the expression of 49 HLA antigens by lymphocytes in patients with gastric cancer.

Six hundred and six patients with histologically confirmed primary adenocarcinoma of the stomach underwent resection from March 1986 to October 1993. We classified these gastric cancer patients into four groups using a simple method of classifying patients according to HLA antigen status.

HLA type I patients had a low level of CD3 and CD4 cells and a high levels of CD16 cells, while HLA type III and IV patients had a high level of CD4 cells and a low level of CD16 cells. HLA type I and III patients, respectively, showed a decreased of CD57 and CD4 cells according to stage. HLA type II and IV patients did not show phenotypic changes of lymphocytes according to stage. These findings show that patients with different HLA types have a differences in immune status. A prospective randomized study using this new classification is now ongoing to confirm its clinical value in gastric cancer patients.
\end{abstract}

Ann Cancer Res Ther 5 (2) : $107 \sim$ 110, $1997 /$ Received 1 Dec 1996, Accepted 20 Dec 1996 Key words: HLA types, gastric cancer, Iymphocyte phenotype

The human major histocompatibility complex (MHC), also referred to as the human leucocyte antigen (HLA) complex, is located on a small part of chromosome 6 . It is by far the most variable part of the genome and initiates immune responses ${ }^{1)}$. Human leucocyte antigens are a group of cell membrane proteins encoded by the HLA complex with a high level of genetic polymorphism that regulate the immune response by self/not-self discrimination. MHC class I antigens are widely distributed on the membranes of almost every cell type, except for erythrocytes and spermatozoa. Unlike class I antigens, class II antigens are only expressed by certain kinds of cells. In humans, they are specifically expressed by macrophages (antigen-presenting cells), B cells, Langerhans cells, dendtritic cells, activated $T$ cells, and other cells of the immune system.

We have previously reported that expression of HLA A2 and B52 or DR4 antigens was respectively associated with a decreased and increased risk of lymph node metastasis in patients with gastric cancer ${ }^{2,3}$. We have also reported that Japanese gastric cancer patients could be divided into four types ( I -IV) by classification according to HLA antigen status for easy analysis of HLA data in the clinical setting ${ }^{4}$.

In the present study, we examined the lymphocyte phenotypes and HLA antigens expression by lymphocytes to evaluate the association between HLA type classified by information on only 21 HLA antigens, and cell-

\footnotetext{
* Department of Surgery, School of Medicine, Tokai University Correspondence to: Kyoji Ogoshi, Department of Surgery, School of Medicine, Tokai University
}

mediated immunity in patients with gastric cancer.

\section{Materials and methods}

Six hundred and six patients with histologically confirmed primary adenocarcinoma of the stomach underwent resection from March 1986 to October 1993. Their ages ranged from 21 to 93 years (median: 60 years), and $70.0 \%$ were men. The patients were staged according to the 1987 Unio Internationalis Contra Cancrum (UICC) pTNM staging system ${ }^{5)}$.

Heparinized peripheral blood samples were obtained from the patients and were centrifuged for $5 \mathrm{~min}$ at 2000 RPM. After collecting the buffy coat, B lymphocytes were separated from $T$ lymphocytes using nylon wool adherence and HLA class I and II Dynabeads (Dynal AS, Oslo, Norway). Peripheral blood lymphocytes were separated by layering onto Lymphoprep (Nycomed, Oslo, Norway) and centrifugation. For class I typing, cryopreserved peripheral blood lymphocytes were subjected to a complement-dependent microcytotoxicity assay using antisera to HLA-A, -B, and -C locus antigens. Class II typing was done on cells enriched for class II-positive lymphocytes using magnetic beads coated with a class II monoclonal antibody (Dynal, Oslo, Norway). These cells were subjected to a complement-dependent microcytotoxicity assay using antisera to HLA-DR and DQ antigens. Lymphocytes were typed for the following 49 antigens: A loci-1, 2, 3, 11, 24, 26, 31, 33 ; B loci-7, 13, 17, 27, 35, $37,39,44,46,48,51,52,54,55,56,59,60,61,62,67$; C loci-wl, w3, w4, w6, w7 ; DR loci-1, 2, 3, 4, 5, 6, 7, 8, 9, 
Table 1 Results of statistical comparison among HLA types according to stage

1. stage $1 \mathrm{~A}$

\begin{tabular}{|c|c|c|c|c|c|c|}
\hline & $\operatorname{cd} 16 \%$ & $\operatorname{cd} 3 \%$ & $\operatorname{cd} 4 \%$ & $\mathrm{CD} 4 / 8$ & cd57\% & $\operatorname{cd} 8 \%$ \\
\hline Chi-Square & 10.461 & 9.029 & 10.541 & 3.332 & 3.555 & 2.693 \\
\hline $\mathrm{df}$ & 3 & 3 & 3 & 3 & 3 & 3 \\
\hline Asymp. Sig. & .015 & .029 & .014 & 343 & .314 & .441 \\
\hline \multicolumn{7}{|l|}{ 2. stage IB } \\
\hline & $\operatorname{cd} 16 \%$ & $\operatorname{cd} 3 \%$ & $\operatorname{cd} 4{ }^{\circ}$ & CD4/8 & cd $57 \%$ & $\operatorname{cd} 8 \%$ \\
\hline Chi-Square & .928 & 1.397 & 2.704 & 3.140 & .362 & 3.796 \\
\hline $\mathrm{df}$ & 3 & 3 & 3 & 3 & 3 & 3 \\
\hline Asymp. Sig. & .819 & .706 & .440 & .371 & .948 & .284 \\
\hline
\end{tabular}

3. stage ?

\begin{tabular}{l|r|r|r|r|r|r}
\hline & cd16\% & $\mathrm{cd}^{3} \mathrm{o}_{\mathrm{o}}$ & $\mathrm{cd}^{0_{0}^{\circ}}$ & $\mathrm{CD} 4 / 8$ & $\mathrm{~cd} 57_{0}^{\circ}$ & $\mathrm{cd} 8 \%$ \\
\hline Chi-Square & 3.521 & 2.927 & .190 & .911 & 2.417 & .610 \\
df & 3 & 3 & 3 & 3 & 3 & 3 \\
Asymp. Sig. & .318 & .403 & .979 & .823 & .490 & .894 \\
\hline
\end{tabular}

4. stage $3 \mathrm{~A}, 3 \mathrm{~B}$

\begin{tabular}{l|r|r|r|r|r|r}
\hline & $\operatorname{cd} 16 \%$ & $\mathrm{~cd} 3^{\circ}{ }_{0}$ & $\mathrm{~cd}^{\circ}{ }^{\circ}$ & $\mathrm{CD} 4 / 8$ & $\operatorname{cd} 57 \%$ & $\operatorname{cd} 8 \%$ \\
\hline Chi-Square & 4.326 & 7.428 & 1.837 & .693 & 1.395 & .108 \\
df & 3 & 3 & 3 & 3 & 3 & 3 \\
Asymp. Sig. & .228 & .059 & .607 & .875 & .707 & .991 \\
\hline
\end{tabular}

\begin{tabular}{l|r|r|r|r|r|r}
\hline 5. stage 4 & \multicolumn{1}{|c|}{} \\
\hline & ${\text { cd } 16^{\circ}}^{\circ}$ & $\mathrm{cd} 3 \%$ & $\mathrm{~cd} 4 \%$ & $\mathrm{CD} 4 / 8$ & $\mathrm{~cd} 57 \%$ & $\mathrm{~cd} 8 \%$ \\
\hline Chi-Square & 2.511 & .952 & 5.621 & 3.971 & 1.442 & 2.305 \\
df & 3 & 3 & 3 & 3 & 3 & 3 \\
Asymp. Sig. & .473 & .813 & .132 & .265 & .696 & .512 \\
\hline
\end{tabular}

10, 12,13; DQ loci-1, 2, 3, 4 All HLA data were obtained preoperatively by a single reference laboratory. The phenotypes of the lymphocytes were also examined by flow cytometry using an Ortho Cytron (Ortho Diagnostic Systems K. K., Tokyo, Japan) and the following antibodies: CD3, CD4, CD8, CDI6 and CD57 (Ortho Diagnostic System K. K., Tokyo, Japan).

We classified the gastric cancer patients into four groups using a simple method of based on HLA antigen status. Type II patients had 2 or more HLA antigens from among A3, A33, B12, B13 and DR6, type III patients had 2 or more HLA antigens from among B46. B54, B55, B56, B59, Cwl, DR4 and DQ4, and type IV patients had 3 or more HLA antigens from among $\mathrm{B} 7, \mathrm{~B} 16, \mathrm{CW} 7$ and $\mathrm{DR} 1$. All other patients were type I . Type I is the commonest type in Japan and does not show any special characteristics.

Statistical analyses were carried our using SPSS 7.0J (SPSS Inc., Chicago, USA.). The nonparametric KuskalWallis and Mann-Whitney $U$ tests were used to determine the significance of differences and a significant difference was defined by $p<0.05$.

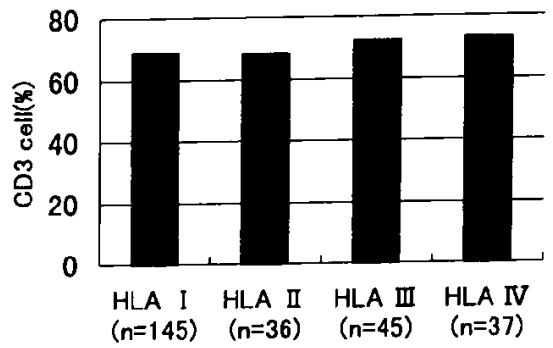

Fig. $1 \mathrm{CD} 3$ cells in stage $\mathrm{A}$ according to HLA type HLA I vs III $; p=0.47$

HLA I vs IV; $p=0.28$

HLA II vs IV : $p=0.26$

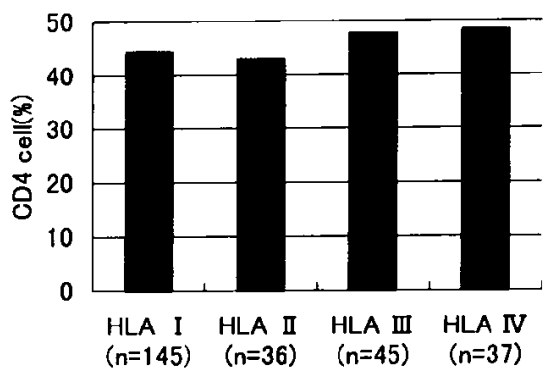

Fig. 2 CD4 cells in stage IA according to HLA type HLA I vs III $; p=0.31$

HLA $I$ vs IV; $p=0.22$

HLA II vs IV : $p=0.01$

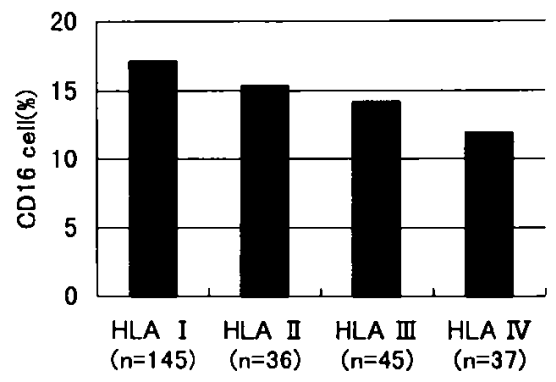

Fig. 3 CDI6 cells in stage IA according to HLA type HLA I vs IV : $\mathrm{p}=0.02$

\section{Results}

By nonparametric analysys, the percentages of CD3, CD4, and CDI6 cells showed significant differences among the HLA types in patients with stage IA gastric cancer, but not in the other stages (Table 1). The percentages of CD8 and CD57 cells and the ratio CD4/8 did not show any significant differences in the other stages. Among stage $1 \mathrm{~A}$ patients, HLA type III and IV patients showed higher levels of CD3 and CD4 cells than those with another HLA types (Fig. 1, 2), while HLA type I patients showed the highest level of CD16 cells (Fig. 3 ).

The percentage of CD57 and CD4 cells showed a significant difference among tumor stages in HLA type I and III patients, respectively (Table 2). Among HLA type 
Table 2 Results of statistical comparison among stages according HLA types

1. HLA type I

\begin{tabular}{l|r|r|r|r|r|r}
\hline & cd 16\% & cd3\% & cd4\% & CD4/8 & cd57\% & cd8\% \\
\hline Chi-Square & 4.253 & 4.876 & 3.672 & 2.888 & 10.409 & 2.854 \\
df & 4 & 4 & 4 & 4 & 4 & 4 \\
Asymp. Sig. & .373 & .300 & .452 & .577 & .034 & .583 \\
\hline
\end{tabular}

2. HLA type II

\begin{tabular}{l|r|r|r|r|r|r}
\hline & cd $16 \%$ & $\mathrm{~cd} 3 \%$ & $\mathrm{~cd} 4 \%$ & $\mathrm{CD} 4 / 8$ & $\mathrm{~cd} 57 \%$ & $\mathrm{~cd} 8 \%$ \\
\hline Chi-Square & 3.932 & 2.739 & 3.822 & 2.924 & 7.525 & 1.707 \\
df & 4 & 4 & 4 & 4 & 4 & 4 \\
Asymp. Sig. & .415 & .602 & .431 & .571 & .111 & .790 \\
\hline
\end{tabular}

3. HLA type III

\begin{tabular}{l|r|r|r|r|r|r}
\hline & $\operatorname{cd} 16 \%$ & $\operatorname{cd} 3 \%$ & $\operatorname{cd} 4 \%$ & $\mathrm{CD} 4 / 8$ & $\operatorname{cd} 57 \%$ & $\mathrm{~cd} 8 \%$ \\
\hline Chi-Square & 7.000 & 5.827 & 10.252 & 5.120 & 7.283 & 2.616 \\
df & 4 & 4 & 4 & 4 & 4 & 4 \\
Asymp. Sig. & .136 & .212 & .036 & .275 & .122 & .624
\end{tabular}

4. HLA type IV

\begin{tabular}{l|r|r|r|r|r|r}
\hline & $\operatorname{cd} 16^{\circ}$ & $\operatorname{cd} 3 \%$ & $\operatorname{cd} 4_{0}^{\circ}$ & $\mathrm{CD} 4 / 8$ & $\operatorname{cd} 57 \%$ & $\operatorname{cd} 8 \%$ \\
\hline Chi-Square & 8.512 & 2.733 & 4.755 & 2.317 & 8.814 & 1.661 \\
df & 4 & 4 & 4 & 4 & 4 & 4 \\
Asymp. Sig. & .075 & .604 & .313 & .678 & .066 & .798 \\
\hline
\end{tabular}

I patients, those with stage $1 \mathrm{~A}$ disease had fewer CD57 cells than those other stages (Fig. 4). Among HLA type III patients, those with stage $1 \mathrm{~A}$ disease showed a higher levels CD4 cells than those in other stages (Fig. 5).

\section{Discussion}

It has been reported that the CD4 coreceptor binds to class II antigens and the CD8 coreceptor binds to class I antigens. It has also been proposed that different HLA class I or class II molecules bind to distinct peptides. Moreover, the CD4-positive killer cell coreceptor also binds to $\mathrm{MHC}$ class II molecules ${ }^{6.7)}$. Therefore, the oncologic significance of HLA antigens is an ongoing matter of debate. Each individual has unique and personal HLA antigens, so we selected HLA antigen status as a parameter of identification.

A recent study demonstrated that MHC class I positive tumors stimulated autologous lymphocytes more frequently than did class I -negative tumors ${ }^{8)}$. In addition, the HLA B locus is adjacent to that for tumor necrosis factor ${ }^{9.10}$. These observations suggest that there may be an association between HLA phenotype and the effectiveness of anticancer therapy, especially immunotherapy.

The clinical implications of our HLA types may be as follows. The present study showed that HLA type I patients had a low level of CD3 and CD4 cells with a high

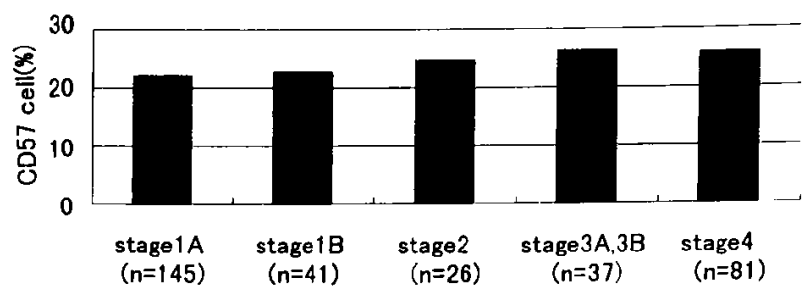

Fig. 4 CD57 cells in HLA type I patients according to stage stage $1 A$ vs $4 ; p=0.01$ stage IA vs $3 \mathrm{~A}, 3 \mathrm{~B} ; \mathrm{p}=0.02$

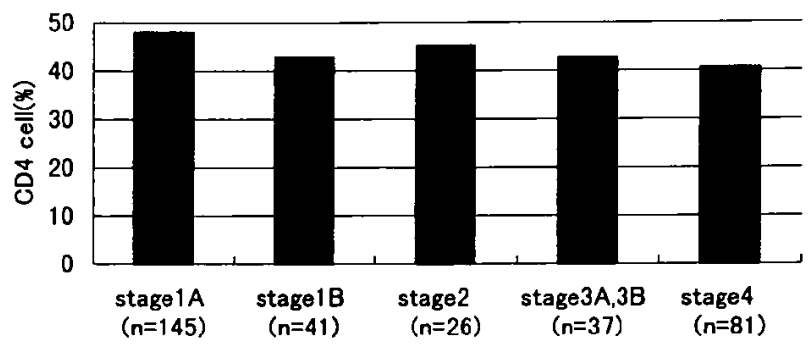

Fig. 5 CD4 cells in HLA type III patients according to stage stage $I A$ vs $4: p=0.006$ stage $1 \mathrm{~A}$ vs $1 \mathrm{~B} ; \mathrm{p}=0.02$

level of CDI6 cells, while HLA type III and IV patients had a high level of CD4 and a low level of CD16 cells. In addition, HLA type I and III patients, respectively, showed a decrease of CD57 and CD4 cells according to stage, but type II and IV patients did not show any change of lymphocyte phenotype according to stages. Thus, the different HLA types showed a different immune status. We have previously presented results suggesting that HLA status could predict the response to anticancer therapy, and have proposed that rational individualized therapy for cancer patients might be designed by evaluating HLA antigens ${ }^{11}$. Development of parameters that correlate with the response of cancer to treatment would allow more rational and suitable use of anticancer therapy. A prospective randomized study using this new classification is now ongoing to confirm its clinical value in gastric cancer patients.

This work was supported in part by a Grant-in-Aid for Cancer Research from the Ministry of Health and Welfare, and a grant from the Japanese Society of Strategies for Cancer Research and Therapy.

\section{References}

1) Boon $T$. A gene encoding an antigen recognized by cytolytic $T$ lymphocytes on a human melanoma. Science, 254: 1643-1647, 1991.

2) Ogoshi K, Tajima T, Mitomi T, Tsuji K. HLA-DR4 antigen and lymph node metastases in poorly differentiated adenocarcinoma of the stomach. Cancer, 73: 2250-2252. 1994. 
3) Ogoshi K, Tajima T, Mitomu T, Tsuji K. HLA antigens are candidate markers for prediction of lymph node metastasis in gastric cancer. Clin Exp Metastasis, $14: 277-281,1996$.

4) Hayashi F, Hayashi C, Ogoshi K. Classification of gastric cancer patients based on HLA antigen expression using quantification method III. Ann Cancer Res Ther, 3: 117-120, 1994.

5) UICC. TNM classification of malignant tumors. In : Hermanek P, Sobin LH, eds. Stomach (ICD-O 15I), 4th ed. New York: Berlin : Heidelberg: Springer-Verlag, 43-46, 1987.

6) Hammer J, Valsasnini P, Tolba K, Bolin D, Higelin J, Takacs $B$, Sinigaglia. Promiscuous and allele-specific anchors in HLA-DR-binding peptides. Cell, 74 : 197-203, 1993.

7) Boon $T$. Teaching the immune system to fight cancer. Science American, March : 32-39, 1993

8) Vanky F, Stuber G, Rotstein S, Klein E. Auto-tumor recogni- tion following in vitro induction of MHC antigen expression on solid human tumors: stimulation of lymphocytes and generation of cytotoxicity against the original MHC-antigennegative tumor cells. Cancer Immunol Immunother, 28 : 17-21, 1989.

9) Spies T, Blanck G, Bresnahan M, Sands J, Strominger JL. A new cluster of genes within the human major histocompatibility complex. Science, 243 : 214-217, 1989.

10) Spies T, Morton CC, Nedospasvo SA, Fiers W, Pious D, Strominger JL. Genes for the tumor necrosis factors a and $b$ are linked to the human major histocompatibility complex. Proc Natl Acad Sci, $83:$ 8699-8702, 1986.

11) Ogoshi K, Mitomi T, Tsuji K, Hayashi C. HLA antigen status and outcome of postoperative adjuvant immunochemotherapy in gastric cancer; A multidimensional data analysis. Ann Cancer Res Ther, 2 : 95-99, 1993. 